\title{
The Representation of Spirituality in Rumi's Selected Poems: An Ecocriticism Analysis
}

\author{
Jamiatus Soleha \\ Universitas Negeri Surabaya \\ Surabaya, Indonesia \\ jamiatussoleha@mhs.unesa.ac.id
}

\author{
Pratiwi Retnaningdyah \\ Universitas Negeri Surabaya \\ Surabaya, Indonesia \\ pratiwiretnaningdyah@unesa.ac.id
}

\begin{abstract}
This study investigates the idea of spirituality in the selected poems of Jalaluddin Rumi, one of the Persian poets who also known as a great Sufi in the world. The objective of this study is to reveal the representation of spirituality through the pastoral images that Rumi employs in his selected poems. By providing textual analysis, this study focuses on pastoral image as one of the components of ecocriticism whereas this field attempts to understand the complexity of relationship within nature. Also, the theory of spirituality is conducted in order to reveal the idea of spirituality. The result of this study shows that pastoral images containing in Rumi's selected poems can be categorized into six groups; chemical element, lands, liquid element, plant, seasonal and solid element. Through those pastoral images the representation of spirituality that Rumi exhibits in his selected poems pervades four aspects; human relation, the meaning of life, the goal of life and transcendence relation.
\end{abstract}

Keywords-ecocriticism; pastoral image; representation; Rumi; spirituality.

\section{INTRODUCTION}

Spirituality is commonly discussed in society and known as a part of religion. Describing the idea of spirituality, the meaning embodies various kinds of interpretation as it is believed as an important aspect of human life which fetches a significant function and power in the life process, therefore, each individual entails this aspect in order to develop a better life. As Hematimoghadam [8] claims that to assist individual dealing with human development, a consideration arises in which a spiritual dimension is required.

A lot of writers depict the idea of spirituality literally and figuratively whether it is through the novel, short story, poem and etc. In order to find out the idea of spirituality, the poem will be used in this study. Different from other literary works, to discover the idea the poet brings through the poem is not easy. It is because the use of language in the poem is more philosophical.

In order to reveal the idea of spirituality, this study utilizes several of Rumi's works. A lot of studies have discussed Rumi's works concerning on spiritual dimension and most of the studies use the spiritual dimension as a device of mental therapy in psychological treatment. Many studies found that people who have mental disorders can be healed through spiritual therapy.

Rumi's works style is similar to others where he conceives various kinds of natural elements. Rumi, in his works, provides five important nature elements; earth, water, air, fire and space in order to demonstrate the idea he brings within. The use of natural elements which appear in the poems commonly comes from the two main sources; land and sea. However, this study will focus on natural elements which emanate from the green world or land area as it is called a pastoral element. Therefore, through this study, the writer will examine the representation of spirituality in Rumi's selected poems. In relation to this, the writer will identify the pastoral images that Rumi employs in his selected poems and use those pastoral images in order to reveal the representation of spirituality in Rumi’s selected poems.

Nature or green world as a part of human living which predisposes the aspect of human life has brought a study of ecocriticism contributes to the study of the relationship between things; human culture and the physical world. Through literary pastoral natural world or a green world is introduced as the only way of modest lessons to teach human being in which the main focus of this field is to understand the complexity of relationships within nature [7]. Through this, it can be seen nature does not only provide human necessity but it predisposes human culture. Glen in Practical Ecocriticism: Literature, Biology, and the Environment claim that land is not only a place of living but also a source of human experience and the foundation for all human thinking, meaning and communication or dialogue [12]. In relation to this, Glotfelty [7] also argues that "human culture is connected to the physical world, affecting it and affected by it" as it reflects nature and man have interconnectedness or reciprocal relationship where both of them affect each other.

Although pastoral images from the outside often wielded nature as a location, it nevertheless transforms as a reflection of the difficult condition of human being and still suggests that it responds human emotions expressing through natural elements such as a tree, wood or even season [6]. As Emily Dickenson, in her nature poems, illustrated that element of nature is a reflection of the harmony between self and nature [4] and Oliver who demonstrates 'earth' as a caring mother which escorts stereotype of a mother who always takes care of her children. Other poets also utilize pastoral images in their works such as Robert Frost, Walt Whitman, Langston Hughes in order to assign a fluid pastoral as "a mechanism of spiritual, cultural, physical renewal and Harlem Renaissance's urban landscape” [10]

Through pastoral images, nevertheless, writers also involve various ideas related to human aspect such as spirituality. Spirituality is believed as the way of human 
being experiences the life in order to find the meaning and purpose and develop connectedness with self, others, nature and with the Scared Source [3].

In order to develop a spiritual dimension, each human being is required to mould an interest toward others; people and the environment. Through this way, each self can be encouraged to find the meaning and purpose of life which influences human beings to strengthen relationship toward the Divine. In relation to this, many spiritual ecofeminists contribute their argumentation on spirituality that it is a crucial factor to determine spiritual quality in which they see spiritual equality influences human life in order to connect self to others including environment as the necessity of human reverence [4].

A study shows that environmental degradation happens because humans constantly never feel satisfied which causes a global crisis happened. A feeling of greedy has brought humans to exploit each natural element through the depletion of resources. The solution has been offered is that to resolve the matter, including the spiritual dimension is required in order to form a new mindset in which attitudinal can be changed [5].

Spiritual dimension has brought a lot of benefits to human life which acquires human being to have a life improvement in which the way people act and behave can be changed preferably. As in the educational system, spiritual education can encourage the young generation to have a better personality.

All-around development of personality can be developed only when spiritual development is given equal system in our education system as other developments are considered important like mental development. Social development, moral development etc [2].

Besides, it is able to heal illness through spiritual therapy. As the study found that mental health can be relieved through spiritual coping mechanisms and helps the clients in the recovery process [13]. Through deep spiritual, the effects of stress can be encountered and shifting to personal personality can occur as it is provoked by life experiences in which human being will be more aware of all aspects of life [11]. In order to evoke spirituality, life experience becomes a vital determination as it is one of the ways for an individual to find some juxtapositions to learn in contrast or complementary. As Burkhardt and Nagai-Jacobson argue that "the experience of living with the known and unknown within the world prompted people to develop beliefs about and codes of conduct for relating to each other, to the sacred and to the natural world”. In relation to this Emily Dickinson in her nature poems argues that nature is a vital dimension for spiritual bailment whereas nature becomes a tool to acquire the harmony as she loves toward nature generates a starting point for the love of life and complete her life as a mankind to access a sense of humanity [4].

\section{METHODS}

This study implicates textual analysis method and conducts a theory of ecocriticism and spirituality in order to reveal the representation of spirituality in Rumi's selected poems. In this case, the data was taken from Rumi's poems translated by Coleman Barks entitled Bridge to the Soul and Jason Espada on My Favorite Rumi. The writer selected eight poems based on the two sources which are A Necessary Autumn Inside Each, A Story They Know, New Blossoms, Leaves About to Let Go, Soul Houses, Mountaintop Through, Desolation and The Dance of your Hidden Life. In order to provide the data, several steps are involved. The first step is collecting the data which requires to do a close reading. After collecting the data, the next step is selecting the data which can be in the form of words, phrases, clauses or sentences in each line or stanza of the poems. In order to answer question number one, the writer will be focused on pastoral images as a part of literary pastoral which is mentioned by Cheryll Glotfelty [7] in Ecocriticism Reader and analyze each meaning of nature elements deeply. In this part, the data will be categorized based on the similarities. While the second research question will be answered by connecting all findings from question number one and elaborate with the approaches.

\section{RESULTS AND DISCUSSION}

1) The Identification of Pastoral Images. In Rumi's selected poems, it is found that Rumi utilizes several figurative languages, types of imagery and various pastoral images. Several figurative languages involve in Rumi's selected poems consist of symbolism, imagery, imagery, simile, hyperbole, metaphor and personification. While types of imagery which appear in this case consist of visual, olfactory, tactile, gustatory and auditory. Besides, pastoral images which Rumi employs in his selected poems are heterogeneous which can be categorized as follow:

\section{A. Chemical Element}

This categorization refers to certain substances which generate a reaction and it can be found in two poems; A Story They Know by the word fire which represents soul purification and New Blossoms by the word 'essences' which represents the various proceeds or a series of life learning.

\section{B. Lands}

This categorization encompasses various parts of the earth which can be found in all of the selected poems. The utilization of land elements in Rumi's selected poems can be divided into two varieties; lowland and highland. In the first variety consists of ground, street/road, orchard, market, garden, world, dust, river and valley. While in the second part only consists of a single element 'mountain'.

\section{Liquid Element}

In Rumi's works, the liquid element can be found in his several selected poems, various liquid elements which have been involved consist of water in $A$ Necessary Autumn Inside Each and New Blossoms, Wax 
in A Story They Know, rain in Leaves About to Let Go, and fountains and lake water in Soul Houses

\section{Plant}

This element pervades a group of a living organism which consists of various kinds of flowers, fruits, trees and plants. These various elements can be found in the six Rumi's selected poems; Mountaintop Trough, The Dance of your Hidden Life, Soul Houses, New Blossoms, A Story They Know and A Necessary Autumn Inside Each.

\section{E. Seasonal}

As the world has four divisions of the season, Rumi employs some seasons in his selected poems in order to deliver his idea. This element appears in A Necessary Autumn Inside Each indicating by the word 'continual autumn' and 'spring'.

\section{F. Solid Element}

This categorization refers to particular hard and strong elements. In this case, Rumi employs three elements consist of rock which can be found in $A$ Necessary Autumn Inside Each, stone in A Story They Know and Soul Houses, and marble in Soul Houses.

2) The Representation of Spirituality. According to Burkhardt \& Nagai-Jacobson, spirituality refers to the way of the human being experiences the life in order to find the meaning and purpose and develop connectedness with self, others, nature and with the Scared Source [3] In relation to this, thus, spirituality can be divided into four aspects; human relation, the meaning of life, the goal of life and transcendence relation.

\section{A. Human Relation.}

As a Muslim, Rumi through his works seems to guide his readers to find out a healthy-living concept that conducts in Islam. As in Quran, Surah an-Nisa; 36 said "Worship God, and ascribe no partners to Him, and be good to the parents, and the relatives, and the orphans, and the poor, and the neighbor next door, and the distant neighbor, and the close associate, and the traveler, and your servants. God does not love the arrogant showoff" [9] which derives a meaning that each mankind needs to have a balanced relationship with the Divine and also others.

In his works, Rumi exhibits some guidance for human beings regarding human relation. To Rumi, human relation does not only build a relation toward other human beings but also toward non-human beings which can lead all of the human beings to find several experiences.

\section{Sit near someone who has had the experience Sit under a tree with new blossom ("New Blossom”)}

Through both lines above, Rumi demonstrates human being should have a balance connectedness between others and nature. It also shows how the poet is close to nature. He loves nature as the tree becomes a place that he chose to sit under. Through this, the poet attempts to express how being close to nature predisposes human's experience where he indirectly depicts nature as a factor in human development. Thus, it can be seen that spirituality and nature construct interconnectedness in which nature predisposes the spiritual dimension in order to develop the balance of human relation. Many spiritual Eco-feminists claim that the interconnection between things, organism, and their environment as a part of "ecological process theology" constitutes spiritual quality [4].

Concerning on experience, in this case, it can be seen that environment is a proponent base in order to cultivate the balance connectedness in human relation whereas through other's experience, an individual can find some juxtapositions to learn in contrast or complementary which reflects the way of spirituality [3] while through connecting self to nature, spiritual quality can be achieved. Learning from other's experience has been mentioned in the Quran Surah Yusuf; 111 as Allah said, "there was certainly in their stories a lesson for those who possess intelligence...” [9].

Besides, in human relation, through his works 'New Blossom' Rumi also depicts how to deal with a social condition.

\section{Instead of that airy commotion \\ Live in the water that gently cools as it flows}

In the first line, the poet reveals that constructing a relationship will lead a human being to face several conflicts. People may argue each other on a certain case in which commotion will happen and it may produce anger, stress, irritation and etc. as it depicts through the phrase 'airy commotion'. Fortunately, Rumi in the second line offers a certain way in order to deal with the condition. As the pastoral image 'water' personifies a peace, Rumi demonstrates a kind of living by being easy to forgive others' mistake in which it leads them to live in harmony in which relationship can be maintained. In one of the studies shows that peace which is acquainted by Rumi can contribute to inter-religious and inter-cultural harmony [1].

The use of liquid element 'water' in this part can be seen as a place as the word 'live' appears. This can be explored further as Rumi tries to convey that by connecting self to nature will affect human culture in which through nature, each individual can learn how to live in peace which can lead self to be capable of maintaining human relation. As Glotfelty [7] claims that, "human culture is connected to the physical world, affecting it and affected by it”.

However, in another poem, instead of arguing each other Rumi suggests all of human being to give benefit toward others

\section{Be the date tree that gave fruit \\ To Mary, the Let-it-be of her heart}

\section{Say a small poem \\ Love the exchange ("Mountaintop Through")}

In the first line, Rumi depicts that each human being should be like a 'date tree' which provides fruit. The interpretation can be seen further that each human being should give benefit to others by helping each other. This is 
also mentioned in Surah Al-Qasas: 77 that God commands all mankind to be charitable [9].

Furthermore, it can be seen that Rumi indirectly attempts to expose equal consciousness by using the word 'be' that each human being should be like the date tree and being able to give mutual feedback as the poet illustrates through phrase 'love the exchange' in which if nature can nourish human beings by supplying fruit, as the mankind each individual should be able to preserve nature. This shows how Rumi respects nature as a part of living and proposes nature as a source of inspiration for a human being in order to establish the reciprocal relationship between human and nature which reflects human culture [7].

\section{Meaning of Life}

In order to find out the meaning of life, according to Rumi, every human being will encounter a process of life where a series of life perceived.

Inside each of us, there's continual autumn. Our leaves

Fall and are blown out ("A Necessary Autumn Inside Each”)

The lines above represent a phase of life where human beings full of weakness as leaves fall which represents strength begins to decrease.

A spring breeze makes everyone laugh

Autumn wakes from his dead sleep

Rose and thorn pair up

... ("The Dance of your Hidden Life”)

In another poem, Rumi demonstrates that every phase of life will lead human being to be aware in which each human being will find a juxtaposition of the complementary opposite where good and bad things will happen as it is represented by the pastoral image 'Rose and thorn'.

In this case, Rumi puts nature as a source of inspiration which can teach human beings in order to find the meaning of life. As self can learn from 'leaves' that they do not always remain to be on the top, but there will be a time for them to fall or about the rose which has thorn as a part of its body in which Rumi declares that in every beauty there will be a wound. This leads to a human being to learn how the meaning of life. Learning through nature, it circumstantially shows the interconnectedness between man and nature which affects spirituality in order to explore the meaning of life. As Chuyan also argues that the interconnectedness toward other things, organism and environment derives spiritual quality as human beings put nature as an encouragement to experience the life [4].

Finding the meaning of life, each human being will encounter several temptations either.

Shoots emerge from a dark core.

The new leaves are tongues ("The Dance of your Hidden Life”)
Through both lines, Rumi portrays that every temptation or difficulty will encourage self-improvement for human beings as new energy exists and moulds strength.

A stone melting to wax, candle becoming moth

On the chessboard a king is blessed again with his queen (“A Story They Know”)

Dealing with several temptations, Rumi in other poems “A Story They Know” expresses that the hardship will not always remain. It will be ease as Rumi depicts in the first line. In the Quran, Surah Al-Insyirah, also mentioned twice that the hardest things happen will be eased (Itani, 2012).

This world of two gardens, both so beautiful

This world, a street where a funeral is passing ("Leaves About To Let Go)

Every temptation that human has in life will lead one realizes that it is a test in order to prepare self for another life; eternity. Although both the world and eternity as Rumi said are beautiful, however, the world becomes a way for leaving.

\section{Goal of Life \\ And you do not arrive here \\ By just straining your neck \\ To look at the mountain}

You must start out and continue on

You have to leave the place ("Mountaintop Through”) ...

In order to find the goal, through the lines above Rumi demonstrates each human being should have an effort by extending different way. again

There's a necessary dying, and the Jesus is breathing

Very little grows on jagged rock

Be ground. Be crumbled, so wildflowers will come up where you are

You've been stony for too many years. ("A Necessary Autumn Inside Each”)

In Rumi’s another poem “A Necessary Autumn Inside Each" shows that endeavour is very necessary which reflects human's personality determines the goal of life.

\section{Transcendence Relation}

Let us rise together and leave this world As water goes bowing down itself to the sea 
From garden to gardener

From grieving to a wedding feast ("Leaves About to Let Go”)

Through the lines above, Rumi demonstrates a relationship toward the Divine whereas through the metaphoric stanza the poet depicts world is grieving and when the world itself is already left and each soul meets the Divine personifies that each of soul has a wedding feast. It carries a meaning that relating self toward the Divine will provide happiness as the phrase 'a wedding feast' appears which visualizes excitement; joy and pleasure are involved in this situation.

Therefore, in order to find real happiness each human being should build a relation toward the Divine.

\section{CONCLUSION}

The result of this study shows that the identification of pastoral images consists of six categorizations; chemical element, land, liquid element, plant, seasonal and solid element. Through those pastoral images, Rumi represents the idea of spirituality which pervades four aspects; human relation, the meaning of life, the goal of life and transcendence relation.

Human relation encourages human development by providing several experiences which can be gained through the interaction towards the environment; human being and non-human being. This aspect also leads each human being to realize that maintaining peace in human relation assists human being to deal with a social problem. Through these conditions, each human being will realize that everything happens in life aims to provide selfimprovement. They, then, should support each other in order to keep the relation by helping others as it is a way to give benefit towards others.
While in the process of finding the meaning of life each human being should, through a life journey where a juxtaposition of the complementary opposite where good and bad things can be found, be aware of the value of life.

\section{REFERENCES}

[1] Abdul Karim Abdullah, "Rumi on education, spirituality and renewal," 2012.

[2] Bilal, S., Ul Rehman, A., Bilal Ahmad Gul, S., \& Ali Naji Qasem, M., "Spirituality a Dimension of All-round Development of Human Personality And Educational Developments," Excellence International Journal of Education and Research, 2013.

[3] Burkhardt, M.A., \& Nagai-Jacobson, M.G. Spirituality: Living Our Connectedness. Albany, NY: Delmar Thomson Learning, 2002

[4] H. Chunyan, "Eco-Feminism in Emily Dickinson's Poetry," Stud. Lit. Lang., vol. 10, no. 3, pp. 63-72, 2015.

[5] G. Duncan, "Celtic spirituality and contemporary environmental issues," HTS Teol. Stud. / Theol. Stud., vol. 71, no. 3, pp. 1-10, 2015.

[6] Garrard, G., Ecocriticism The New Critical Idiom. The New Critical Idiom (Vol. 1), 2015.

[7] Glotfelty, C., \& Fromm, H., The Ecocriticism Reader Bffi LANDMARKS IN LITERARY ECOLOGY "Some Principles of Ecocriticism", British Library Cataloging in Publication Data available, 1996.

[8] Haji, L., \& Taghia, S., "Investigating of Spiritual Therapy Factors Based on Rumi: Study of the Elements of Spiritual Therapy Based on Mawlānā Works," International Journal of Scientific Study, vol. 5, no. 3, 2017.

[9] Talal Itani, Qur'an TRANSLATED BY TALAL ITANI Quran. 2012.

[10]Loveland, M. E., The Fluid Pastoral: African American Spiritual Waterways in the Urban Landscapes of Harlem Renaissance Poetry, vol. 11, no. 1, 2018.

[11]Pandya, S. P., "Spirituality and Social Work: Some Deliberations," The Indian Journal of Social Work, vol. 72, no. 1, pp. 91-116, 2011

[12] Taitano, M., Landscape of Change: An Ecocritical View of Willa Cather's, vol. 24, no. xix, pp. 1-18, 2015

[13] Wiedmeyer, N., Carlson, K., Peterson, M., \& Anez, E., Spirituality in Social Work: Therapists' Perspectives on the Role of Spirituality Within their Practice Spirituality in Social Work: Therapists' Perspectives on the Role of Spirituality Within their Practice Role of Spirituality in Therapy 2 Acknowledgmen, 2013. Retrieved from http://sophia.stkate.edu/msw_papers/273 